REDES- Revista hispana para el análisis de redes sociales

Vol. 24,\#2, Diciembre 2013

http: // revista-redes. rediris.es

\title{
Redes negativas: el pequeño mundo de las hinchadas de fútbol
}

\author{
Juan Sebastián Bundio- Consejo Nacional de Investigaciones Científicas y Técnicas \\ (CONICET), Instituto de Investigaciones Gino Germani (IIGG) y Universidad de \\ Buenos Aires (UBA) ${ }^{\mathbf{1}}$
}

\begin{abstract}
Resumen
La red de rivalidades entre barras bravas argentinas exhiben propiedades de mundo pequeño. Esta red reúne datos para 247 grupos de simpatizantes de Argentina. Es la primera vez que se demuestra que una red negativa puede poseer un elevado coeficiente de agrupamiento $(0,282)$ y una pequeña distancia media $(4,833)$. En el presente estudio se indagarán los mecanismos que podrían explicar por qué la red posee estas propiedades. Se propone la hipótesis de que la forma en que se organiza la competencia deportiva afecta la estructura de la red de rivalidades entre simpatizantes argentinos.
\end{abstract}

Palabras clave: Fútbol - Redes negativas - Rivalidades - Mundo Pequeño.

\section{Abstract}

The rivalries network between the argentine barras bravas exhibits small-world properties. This network was constructed with data of 247 groups of Argentinians supporters. This is the first time that it is shown that a negative network can exhibit a large clustering coefficient (0.282) and a small average distance (4.833). In the present study I inquire into the mechanisms that might explain why the network has these properties. It is hypothesized that the sports competition organization affects the network structure of rivalries.

Key words: Soccer - Negative networks - Rivalry - Small World

\section{Introducción}

La violencia en el fútbol constituye un grave problema social en Argentina. La ONG Salvemos al Fútbol $^{2}$, mantiene una lista actualizada de las muertes en este deporte, que en el periodo 1922- 2012 arroja un saldo de 271 víctimas fatales. En promedio mueren 3 simpatizantes de fútbol por año en Argentina, trágicamente ese valor se incrementó de manera notable en las dos últimas décadas.

\footnotetext{
${ }^{1}$ Enviar correspondencia a:Juan Sebastián Bundio (jsbundio@sociales.uba.ar)

${ }^{2}$ http://www. salvemosalfutbol.org
} 
Buena parte de los episodios de violencia están asociados a un actor específico: las barras-bravas. Las barras son grupos de simpatizantes que mantienen un vínculo económico o instrumental con el club, y que interpretan la violencia en el marco de nuevas moralidades vinculadas a concepciones de masculinidad y pertenencia grupal.

La hostilidad entre estos grupos aumenta cuando ambos se consideran rivales "clásicos". Esta hostilidad se manifiesta a nivel simbólico en los cánticos, pero también en la agresión física y el enfrentamiento directo. Puesto que la mayoría de estos enfrentamientos ocurre en las inmediaciones de los estadios durante el desarrollo de los partidos resulta imperativo preguntarse por el papel que cumple la competencia deportiva en la evolución del conflicto.

La violencia y la agresión entre simpatizantes pueden ser pensadas como datos reticulares. Después de todo constituyen relaciones sociales por derecho propio. No sólo las "relaciones positivas" vinculan a las personas y grupos, también las "relaciones negativas" tienen un peso considerable en la estructuración y evolución de las redes humanas.

El estudio de la red negativa entre barras bravas no sólo posibilita un abordaje novedoso al problema de la violencia entre simpatizantes, sino que además permite indagar la estructura que tienen las redes negativas a gran escala. ¿Puede una red negativa ser un mundo pequeño? ¿Cuál puede ser su dinámica? ¿Son útiles los conceptos y métricas de redes para su estudio?

\section{Hinchadas y redes: hacia un enfoque reticular de la violencia en el fútbol}

\section{Redes negativas, un campo apenas explorado}

En los últimos 10 años ha crecido el interés en las llamadas redes negativas (Robins \& Pattison, 2006). Entre los trabajos más sobresalientes en este campo pueden mencionarse los estudios sobre redes personales negativas en organizaciones (Joshi, Labianca, \& Caligiuri, 2002; Labianca \& Brass, 2006; Robins \& Pattison, 2006), redes de homicidios entre bandas delictivas (Papachristos, 2009), redes de rivalidades y alianzas entre pandillas norteamericanas (Nakamura, Tita, \& Krackhardt, 2011), redes de acusaciones durante la Inquisición Española (Bergemann, 2012), redes de afinidades y rechazo a clubes españoles de fútbol (Maya \& Bohórquez, 2011), entre otros. 
La multiplicidad de fenómenos estudiados desde distintas perspectivas teóricas no ha contribuido a la consolidación de un consenso acerca de qué es una relación negativa o una red negativa. Una de las posibles definiciones es aquella dada por Labianca y Brass (2006): "Negative relationships represent an enduring, recurring set of negative judgments, feelings, and behavioral intentions toward another person - a negative person schema".

Los distintos trabajos con redes negativas se han visto obligados a ajustar sus definiciones a las particularidades del objeto de estudio que abordan. De hecho la definición arriba mencionada no es del todo adecuada para el presente trabajo que aborda las relaciones de rivalidad entre grupos específicos de simpatizantes del fútbol argentino, conocidos como barras bravas.

Algunas investigaciones con redes negativas que echan mano de algún tipo de modelado recurren al modelo de equilibrio o balance social propuesto por Heider para el estudio de las actitudes (Heider, 1946), y extendido posteriormente para abarcar las relaciones entre personas y grupos sociales (Cartwright \& Harary, 1956). Tal es el caso del mencionado estudio sobre pandillas norteamericanas de Nakamura et al. (Nakamura, et al., 2011). Esta investigación constituye un saludable intento de analizar las estructuras de redes desde un enfoque dinámico, pero no deja de ser marginal en relación a la mayoría de investigaciones que hacen un uso sincrónico del Análisis de Redes Sociales (ARS).

\section{Redes complejas y paradigmas de modelado}

Todavía no se ha intentado adecuar los llamados paradigmas tradicionales de modelado de redes complejas a la investigación con redes negativas (Albert \& Barabási, 2002). Estos paradigmas incluyen el modelo de redes aleatorias, el modelo de mundo pequeño y el modelo libre de escala.

Los modelos de redes aleatorias son variantes del modelo de Erdös y Rényi (1959), quienes demostraron que la evolución de las redes aleatorias conduce a la red a una estructura de una única componente gigante. En una estructura de este tipo siempre es posible encontrar un camino entre un par de nodos escogidos al azar, de ahí que estas redes tengan una baja media de las distancias geodésicas.

Los modelos de redes de mundo pequeño fueron propuestos por Watts y Strogatz (1998). Estos autores plantearon un modelo de red a partir de una grilla regular 
agrupada y de la recombinación aleatoria de sus vínculos. Este modelo partía del supuesto de que existen agrupamientos (clusters) en una red social, agrupamientos generados por la pertenencia de los individuos a grupos de afiliación. La pertenencia de unos pocos de estos individuos a más de un grupo social, les permite funcionar como atajos entre los grupos.

Los autores plantearon que la existencia de mecanismos que generan un agrupamiento y una media pequeña de distancias geodésicas, son necesarios y suficientes para generar una red de mundo pequeño. Es decir, un mundo pequeño es una red en donde un nodo cualquiera puede acceder a cualquier otro en una serie corta de pasos, y que a la vez manifiesta un elevado agrupamiento que la diferencia de las redes aleatorias, sirviendo como modelo alternativo del modelo Erdös-Rényi.

Por último están los modelos de redes libres de escala, propuestos por Barabási y Albert para el estudio de la dinámica de la red y del origen de las distribuciones de grado (1999). Típicamente las redes libres de escala implican mecanismos distintos a los propuestos por el modelo Watts-Strogatz y que son importantes para comprender la dinámica del sistema: el crecimiento de la red y el enlazamiento preferencial (preferential attachment).

Este modelo explica la evolución de la web señalando que la existencia de hubs o nodos muy conectados depende de la preferencia de las nuevas webs a linkearse a otras que están bien conectadas como estrategia para aumentar su propia conectividad. La dinámica de estas redes lleva a que unos pocos nodos tengan muchísimos vínculos, mientras que la mayoría tiene pocos, característica observable en la distribución potencial de la cantidad de nodos en función de su grado nodal (degree).

Vinculados a los modelos mencionados existen tres conceptos que ocupan un lugar prominente en el estudio de las redes complejas y que sirven a los propósitos de su caracterización (Albert y Barabási, 2002):

1) Pocos grados de separación (path length). A pesar del enorme tamaño de las redes complejas existen relativamente pocos pasos de distancia entre dos nodos tomados al azar. La media de las distancias geodésicas entre los nodos es pequeña. Las redes aleatorias son redes pequeñas ya que la distancia típica entre dos nodos disminuye a medida que aumenta su conectividad, las redes de mundo pequeño son pequeñas porque existen atajos entre agrupamientos. No siempre una red es pequeña por los mismos motivos. 
2) Agrupamiento (clustering). Es una propiedad común en las redes sociales la formación de clusters, que representan grupos de amistades (o cualquier otro tipo de relación social) en donde cada miembro es amigo de (o está vinculado a) todos los demás. Esta tendencia puede medirse reticularmente con el coeficiente de agrupamiento (clustering coefficient). En las redes de mundo pequeño este coeficiente es mucho mayor que en redes aleatorias del mismo tamaño y densidad.

3) Distribución de grado libre de escala (scale-free degree distribution). La probabilidad de que un nodo escogido al azar tenga una cantidad determinada de vínculos sigue una distribución de ley de potencia, alejada de una distribución de Poisson característica de las redes aleatorias. En estas redes unos pocos nodos están muy bien conectados mientras que la mayoría no lo están. Estas redes también poseen un elevado agrupamiento y una pequeña media de las distancias geodésicas debido a la alta conectividad de los hubs o nodos centrales. Al igual que en el caso de los grados de separación, el agrupamiento de la red puede deberse a distintos motivos.

Existe una abundante literatura que hace uso de estos modelos para explicar las propiedades de redes complejas, que podrían denominarse positivas. Estas redes representan fenómenos tan diversos como la conectividad de la World Wide Web (Barabási \& Albert, 1999), las colaboraciones actorales (Watts \& Strogatz, 1998), las colaboraciones científicas (Newman, 2001), las redes lingüísticas (Ferrer i Cancho \& Solé, 2001), la sociabilidad de los delfines (Lusseau, 2003), y muchas otras. Sin embargo se plantean interrogantes sobre la adecuación de estos modelos a las redes negativas. Sobre todo en lo referido a la interpretación de medidas y algoritmos pensados para redes positivas como la transitividad, la reciprocidad, la densidad, la homofilia, entre otras.

\section{Etnografías de grupos de simpatizantes en Argentina}

Las prácticas violentas entre grupos de simpatizantes argentinos fueron ampliamente tratadas en la literatura etnográfica. Se entiende por rivalidad un conjunto recurrente de prácticas, actitudes y prejuicios asociados a una la hostilidad recíproca. Hostilidad manifestada por los distintos grupos de simpatizantes en cánticos, símbolos y, en algunas ocasiones, mediante actos violentos. 
No todas las prácticas violentas ocurren entre grupos de simpatizantes enemigos, pero sí la gravedad y cantidad de incidentes parecen incrementar en presencia de una enemistad. Esto puede deberse en parte a que las rivalidades futbolísticas son constitutivas de las identidades grupales, siendo común que se represente al otro social como una alteridad radical. Además los simpatizantes recurren a diferenciaciones deportivas para expresar conflictos que están vinculados a distinciones de otra índole, como las oposiciones de clase, de etnia, de territorio, de género, etc. Existen además casos de rivalidades que tienen sus orígenes en los momentos fundacionales de las instituciones deportivas, como es el caso de la rivalidad entre los simpatizantes de Boca Juniors y River Plate, o entre sus pares de Independiente y Racing.

En Argentina estas rivalidades se manifiestan en ocasiones mediante la agresión física. Las prácticas violentas aparecen asociadas a un actor específico: las barras bravas, grupos organizados de simpatizantes que participan de la vida económica y política del club. Si bien en todo espectáculo existe una multiplicidad de violencias posibles, llevadas a cabo por distintos actores sociales, en el lustro 2006-2010, 29 de las 32 muertes acontecidas en el fútbol argentino se debieron al accionar directo de barras bravas (Sustas, 2011).

Los barras conciben la violencia como criterio de pertenencia al grupo dentro de una lógica que se ha dado en llamar "cultura del aguante" (Alabarces, Garriga, \& Moreira, 2008). En efecto, se ha argumentado que la violencia entre simpatizantes debe comprenderse a partir de los marcos interpretativos nativos que le dan un sentido. El aguante es una categoría nativa que resume un ideal masculino agresivo donde los saberes corporales delimitan quién está adentro y quién está afuera de la barra. EI aguante es un bien simbólico que no sólo se posee sino que debe probarse y actualizarse continuamente a través de las prácticas violentas, las gestualidades y el lenguaje agresivo.

De trabajos etnográficos con grupos de simpatizantes, vale destacar la investigación de Moreira (2001) quien analiza la inserción de las prácticas violentas en los sistemas valorativos y evaluativos de estos grupos. La autora señala que estas prácticas se originan en disputas por las formas específicas que adquiere el honor masculino en estos grupos sociales (Moreira, 2005). Por su parte Garriga ha estudiado la violencia entre grupos de simpatizantes como generadora de jerarquías, relaciones y cohesión social al interior del colectivo, investigando también las vinculaciones entre estas prácticas y las identidades de género masculinas (Garriga, 2007). 
Alabarces menciona el papel de la competencia deportiva como desencadenante de conflictos sociales entre simpatizantes (2004), anticipándose a la hipótesis de que la forma en que se organiza la competencia podría condicionar el establecimiento de las relaciones negativas entre grupos de simpatizantes. Gil caracteriza el establecimiento de enemistades o rivalidades entre grupos de simpatizantes como mecanismos de reciprocidad negativa (2008a), de manera que las rivalidades podrían conducir hacia un recrudecimiento de la violencia mediante un mecanismo de feed-back positivo. En este marco las alianzas entre barras bravas surgirían para enfrentar a enemigos comunes (Garriga, 2002). Esto último es evidenciado por la presencia significativa de tríadas balanceadas de dos rivalidades y una alianza señaladas en un trabajo anterior (Bundio, 2012a). Estos trabajos plantean la posibilidad de que la estructura de los torneos de fútbol en Argentina pueden ser factores que alteran las vinculaciones negativas entre los grupos de barras.

\section{Primeros análisis de las redes de barras bravas}

Los trabajos etnográficos realizados en el campo de la antropología del deporte apoyaban la idea de que la red negativa de rivalidades entre barras bravas tenía la estructura de una red aleatoria. El argumento era que si la lógica imperante en este campo es la de probar la posesión del bien simbólico aguante frente a las barras rivales, la red de rivalidades debería ser aleatoria porque en principio no se habían identificado factores que influyeran en el establecimiento de enemistades.

Esta deducción vuelve contra-intuitivo el descubrimiento de que la red de rivalidades entre simpatizantes forma un mundo pequeño (Bundio, 2011, 2012b). En efecto, ella posee un elevado coeficiente de agrupamiento y una pequeña media de la distancia, siendo ambos resultados significativos (ver iError! No se encuentra el origen de la referencia., Ilustración 1 e Ilustración 2$)^{3}$.

\footnotetext{
${ }^{3}$ Los algoritmos tradicionales pensados para la descripción de redes complejas presentan inconvenientes. Recientemente se ha llamado la atención de que la presencia de nodos aislados afecta el cálculo de los coeficientes de agrupamiento (Kaiser, 2008). Por otro lado se ha demostrado que es necesario recurrir a nuevas técnicas para estimar los parámetros de una red libre de escala (Clauset, Rohilla Shalizi, \& Newman, 2009). De esta manera muchas redes que aparentaban tener distribuciones de ley de potencia no lo eran en absoluto. Otras que aparentaban ser redes aleatorias terminaron categorizándose como mundos pequeños.
} 


\begin{tabular}{|c|c|c|c|c|c|c|}
\hline Redes & Nodos & Densidad & $\begin{array}{c}\text { Coef. } \\
\text { Agrupamiento }\end{array}$ & $\mathbf{P} \geq \mathbf{0}$ & $\begin{array}{c}\text { Distancia } \\
\text { Media }\end{array}$ & $\mathbf{P} \geq \mathbf{0}$ \\
\hline Rivalidad & 247 & 0,0172 & 0,282 & 0,000 & 4,833 & 0,000 \\
\hline Competición & 247 & 0,1148 & 0,588 & 0,000 & 2,724 & 0,000 \\
\hline
\end{tabular}

Tabla 1. Coeficientes de Agrupamiento y Distancia Media para las redes de Rivalidades y Competencia. Se ejecutó un test de significancia sobre 1000 simulaciones.

En trabajos anteriores se analizó el papel de la proximidad geográfica en el establecimientos de alianzas entre grupos de simpatizantes (Bundio, 2011). Se pudo identificar que las alianzas se establecen generalmente entre grupos que no pertenencen a la misma ciudad y provincia. De esta manera las alianzas vinculan territorios alejados, siendo minoritarias las amistades entre hinchadas que son cercanas geográficamente.

Además se evaluó la influencia de las alianzas entre barras en la formación de tríadas "balanceadas" (Bundio, 2012a). Los resultados muestran que la presencia de tríadas de dos aliados vinculados por un enemigo en común es estadísticamente significativa pero no explica la totalidad de las alianzas. La mayoría de las tríadas vinculan tres hinchadas mediante vínculos negativos. En contra del sentido común de los simpatizantes y académicos, el enemigo de mi enemigo, es mi enemigo. ¿Cómo se puede explicar este fenómeno de agrupamiento negativo?

\section{Materiales, hipótesis y técnicas}

La hipótesis que aquí se mantiene es que la competencia deportiva, organizada territorialmente, delimita el espacio dentro del cual las barras argentinas establecen relaciones de rivalidad. Para poner a prueba esta hipótesis se evaluó la importancia de dos factores: la cantidad de partidos jugados entre las instituciones deportivas en los últimos 10 años, y la proximidad geográfica representada por la localización de los estadios en una misma ciudad y provincia. Se espera que la red Rivalidad esté incluida en la red Competición, y que exista un elevado grado de homofilia a partir de la pertenencia territorial provincial y municial. De esta manera se propone que el sistema de competencia deportiva es el factor que explica el elevado agrupamiento de la red negativa. Para poner a prueba la hipótesis, se relevaron datos reticulares y atributivos 
para 294 barras bravas de todas las divisiones deportivas, incluyendo instituciones vinculadas directa e indirectamente con la Asociación de Fútbol Argentino ${ }^{4}$.

Los datos reticulares necesarios para la construcción de la red Rivalidad y de las tablas de atributos se obtuvieron de la web Barras-Bravas.com ${ }^{5}$. Esta web tenía como objetivo ser un lugar de encuentro y de intercambio para los barras argentinos, y mantenía actualizada una base de datos con información de las barras a partir de información suministrada por los propios miembros.

A tal efecto los administradores de la web confeccionaban fichas de cada barra argentina a partir de mails de lectores. Dichas fichas aportaban datos referidos a: nombre de la hinchada y/o de la barra brava, localización del estadio y la sede, formas seguras de llegar al estadio, hinchadas rivales, hinchadas amigas, últimos enfrentamientos con la policía o con otras hinchadas, fotos y videos de la hinchada y/o barra, fotos de banderas de hinchadas rivales robadas (llamadas "trapos"), canciones y fotos de grafitis (llamados "pintadas").

Al mencionar las enemistades de cada barra, en pocas fichas se hacía referencia a si esta relación era entre hinchadas o entre barras ${ }^{6}$. En Argentina se usa el nombre genérico de hincha para referirse a cualquier simpatizante de un equipo de fútbol. Mientras que se reserva el término barra para hacer referencia a grupos de hinchas vinculados económicamente con el club, y generalmente asociados a prácticas violentas. En el caso argentino es posible que una enemistad entre barras no lo sea entre otros actores del mismo grupo de simpatizantes ${ }^{7}$, aunque el caso contrario es improbable, ya que las barras se conciben a sí mismas como el sector más fanático de un grupo de simpatizantes (Alabarces, 2004).

\footnotetext{
${ }^{4}$ De esta manera se ampliaron y revisaron datos utilizados en trabajos anteriores y que incluían a 186 barras bravas (Bundio, 2011, 2012a, 2012b).

${ }^{5}$ http://www. barras-bravas.com

${ }^{6}$ Uno de los supuestos implicados en la construcción de la red es que las enemistades manifestadas en Barras-Bravas.com se dan entre barras bravas y no entre la mayoría de simpatizantes de fútbol. En la web se detectaron menciones que distinguen lo que es una enemistad de barras de una enemistad de simpatizantes, por lo que se puede suponer que las rivalidades entre barras exceden a las rivalidades entre simpatizantes. Sin embargo no se tiene la certeza de que esto sea así.

${ }^{7}$ Por ejemplo los simpatizantes de Independiente mantienen una fuerte amistad con los simpatizantes de Newell's Old Boys a pesar de que las barras de ambos grupos son hostiles entre sí.
} 
Puesto que los datos necesarios para construir la red Rivalidad no estaban estructurados, fue necesario construir el dato reticular. Para dicha tarea se procedió a realizar un listado de vínculos en una planilla Excel que posteriormente fue importado y convertido a matriz.

Los datos para la construcción de la red Competición se obtuvieron de la web de la Rec.Sport.Soccer Statistics Foundation ${ }^{8}$. Esta web mantiene actualizada una enorme base de datos con resultados de partidos de fútbol jugados en las principales ligas mundiales. Estos datos, al igual que los presentes en la web de Barras-Bravas.com, no estaban en formato reticular. Por tal motivo se recolectaron los partidos jugados entre las 294 instituciones deportivas durante el periodo 2001-2010 y se elaboró un listado de vínculos que posteriormente fue convertido a matriz ${ }^{9}$. Puesto que no se obtuvieron datos reticulares para partidos jugados por 47 instituciones que disputan competencias no oficiales, no se tuvieron en cuenta en el análisis. De este modo ambas redes incluyen a 247 instituciones con sus respectivos grupos de barras bravas. Los datos fueron analizados con el software ORA $\odot$ 2.3.6, y las visualizaciones fueron creadas mediante NodeXL@1.0.1.229.

El conjunto de datos incluye las redes: 1) Rivalidad: relaciones hostiles recíprocas entre los grupos de simpatizantes (Ilustración 1); 2) Competición: cantidad partidos jugados entre los años 2001 y 2010 entre las instituciones identificadas con los grupos de simpatizantes mapeados (Ilustración 2).

\footnotetext{
${ }^{8}$ http://www.rsssf.com

${ }^{9}$ Todos los datos fueron relevados en el marco de la tesis de licenciatura del autor, entre los años 2009 y 2010, fecha en la cual la web Barras-Bravas.com dejó de estar online. Por tal motivo los datos reflejan el estado de las enemistades en el año 2010.
} 


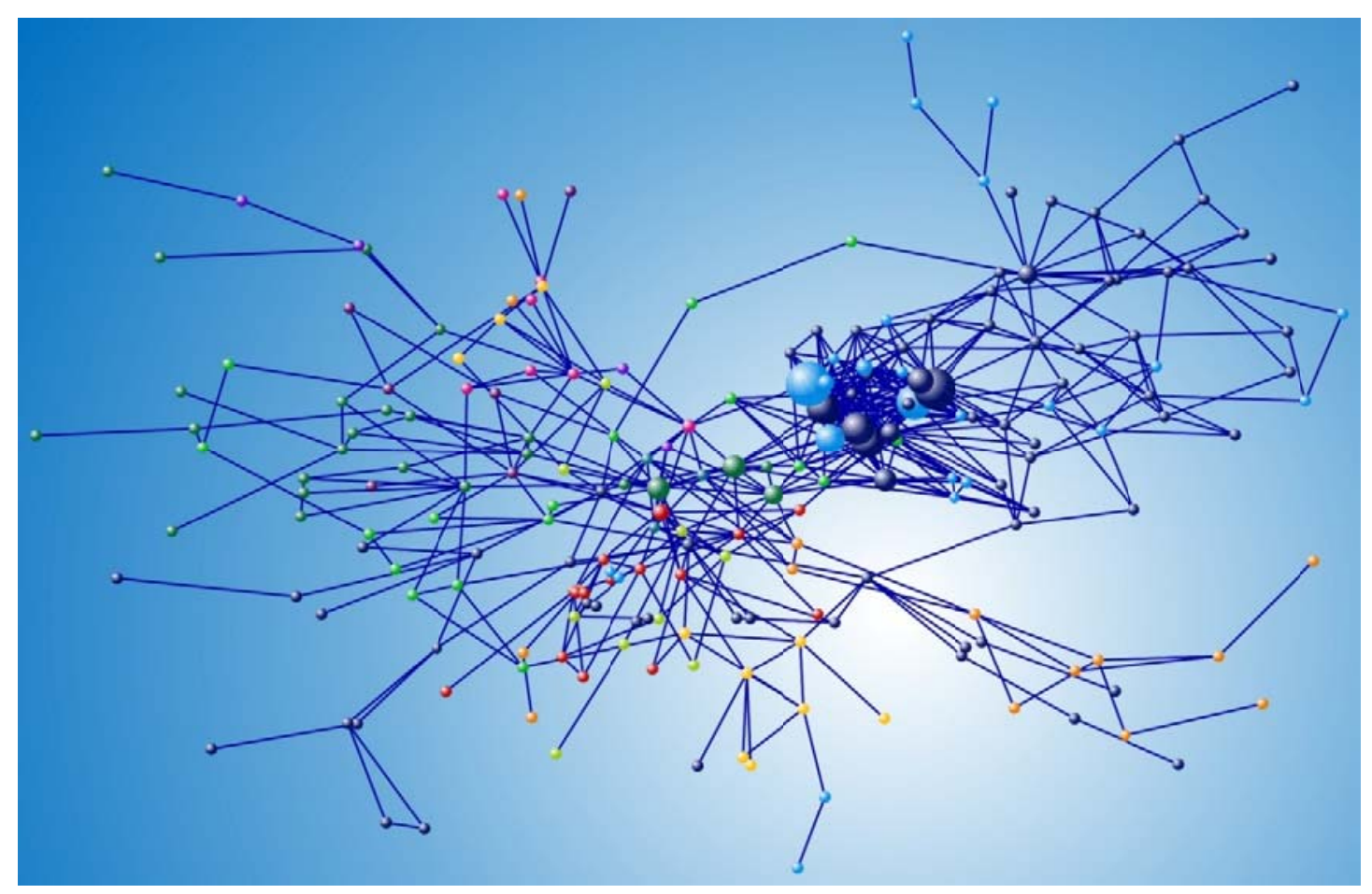

Ilustración 1. Red Rivalidad coloreada por la provincia de pertenencia.

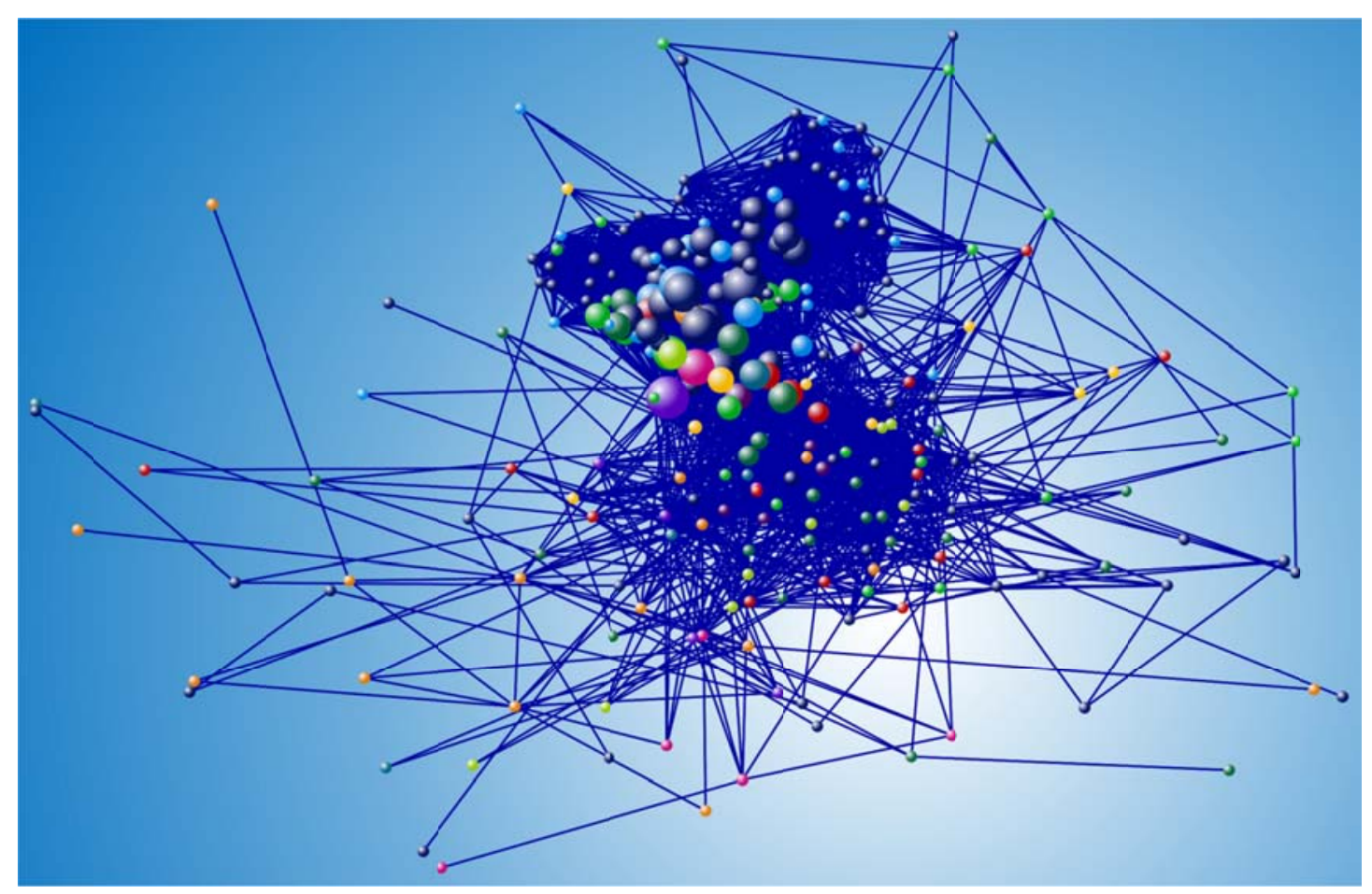

Ilustración 2. Red Competición coloreada por provincia de pertenencia. 
Además se confeccionó una tabla de atributos a partir de información presente en la web Barras-Bravas.com que contienen datos de adscripción territorial por Provincia (nivel provincial) y Ciudad (nivel municipal) para cada uno de los grupos. Para esta tabla se partió del supuesto de que la localización del estadio en una ciudad y provincia coincide con la localización de los simpatizantes, algo que no siempre es correcto. En el caso de las hinchadas nacionales (como las hinchadas de Boca, River, Independiente, Racing y San Lorenzo) es habitual encontrar simpatizantes por fuera del barrio, ciudad o provincia donde se localiza el estadio. A pesar de ello, la localización del estadio les permite a los hinchas ubicar el centro simbólico de un territorio pensado como propio y que trasciende los límites territoriales reales del grupo (Alabarces, 2004) ${ }^{10}$.

Se tomaron medidas para garantizar la fiabilidad de los datos. La red Rivalidad fue simetrizada por el método mínimo con el objetivo de reducir posibles errores en la carga e inconsistencias en los datos. De esta manera no se calculó la reciprocidad de la red quedando pendiente la pregunta de si todas las enemistades son recíprocas ${ }^{11}$.

La red Competición es una red simétrica desde un principio por la naturaleza del dato. Es además una red valuada ya que sus vínculos poseen un peso dado por la cantidad de partidos jugados. Para el análisis esta red fue dicotomizada en distintos umbrales de corte con valores de 5,10,15,20,25.

Actualmente el sistema de categorías posee 5 niveles, de los cuáles sólo los dos primeros aglutinan instituciones de todo el país. Estas divisiones son la Primera A (20 equipos), y el Nacional B (20 equipos). A partir de aquí, los equipos que descienden de categoría vuelven a ligas regionales. Los equipos de Capital Federal y Gran Buenos Aires descienden a la Primera B ( 21 equipos) ${ }^{12}$, mientras que los equipos del resto del país descienden al Torneo Argentino A (25 equipos). De esta manera se reproduce una vieja división en el imaginario popular argentino entre equipos "porteños" y equipos del "interior". De la Primera B se desciende a la Primera C (20 equipos), a la Primera D

\footnotetext{
${ }^{10}$ Los hinchas de Boca Juniors, que tiene su estadio en el barrio porteño de La Boca, se imaginan como pertenecientes a ese barrio, a pesar de que Boca Juniors lidera las encuestas de adhesión deportiva en la mayoría de las provincias del país.

${ }^{11}$ Ciertos casos señalan que no todas las enemistades son recíprocas. Los simpatizantes de Arsenal de Sarandí reconocen como enemigos a sus pares de Independiente, sin embargo los simpatizantes de Independiente ven a los de Arsenal con cierta simpatía o menosprecio, según el caso, pero no como enemigos.

12 Los equipos que descienden por esta rama son aquellos afiliados directamente a la Asociación de Fútbol Argentino. En total son 87 equipos, de los cuáles 6 de ellos se ubican en la provincia de Santa Fe.
} 
(18 equipos) y luego a la desafiliación por 1 año. Del Torneo Argentino A se desciende al Torneo Argentino B (100 equipos organizados en ligas regionales con instancias superiores nacionales) y al Torneo de Interior (325 equipos organizados en ligas regionales con instancias superiores nacionales).

Puesto que la mayor parte de la competencia futbolística en Argentina está organizada regionalmente, y sólo en las instancias superiores se enfrentan equipos de todo el país, es esperable que no sólo exista una correlación entre rivalidades y competencia, sino también entre rivalidades y cercanía territorial. Por tal motivo se evaluó no sólo el papel de la competencia como desencadenante de conflictos, sino también la homofilia territorial.

La estructura del sistema de categorías deportivas del fútbol argentino ha variado mucho a lo largo del tiempo. Se pasa de 1 división a 3 divisiones en 1935, a 4 divisiones en 1950 y a 5 divisiones en 1986. La estructura descripta se origina en la re-estructuración del 2005, por la cual se incorporan las ligas del interior al sistema de competencia.

La conjunción de atributos relacionales y no relacionales permite elaborar una tipología de actores y relaciones. Identificar la presencia y frecuencia relativa de cada uno de estos tipos permite evaluar el peso de distintos factores que están vinculados con las enemistades. La tipología de actores/relaciones incluye a los Rivales (vinculados en la red Rivalidad), los Competidores (vinculados en la red Competición) y los Cercanos (comparten atributo de pertenencia territorial). Dentro de estos últimos se distinguen a los Provinciales (comparten el atributo Provincia) y a los Municipales (comparten el atributo Ciudad).

Además se analizó la distribución de los grados nodales en las redes de Competición y Rivalidad. Es esperable que si la hipótesis es correcta las barras que más rivales tienen sean aquellas que más rivales enfrentaron en lo deportivo.

\section{Análisis y resultados}

La probabilidad de que dos grupos de simpatizantes sean enemigos es mayor mientras más partidos hayan disputado las instituciones deportivas con las que se identifican estos grupos. El análisis de la intersección entre la red Rivalidad y la red Competición binarizada permite distinguir entre rivales competidores (vinculados en ambas redes), rivales no competidores (vinculados sólo en la red Rivalidad), neutrales competidores 
(vinculados sólo en la red Competición) y neutrales no competidores (no vinculados en ninguna red). El 77,10\% de los vínculos en la red Rivalidad están presentes entre mismos nodos en la red Competición binarizada ${ }^{13}$. Esta tendencia señala que del total de rivales la mayoría son rivales competidores, y el $22,90 \%$ son rivales no competidores.

De los vínculos presentes en la red Competición binarizada, el 11,58\% está presente en la red Rivalidad (rivales competidores sobre el total de competidores). Este valor indica que no existe una relación directa entre la competencia deportiva y el establecimiento de enemistades pero si una tendencia. Este valor se incrementa si comparamos los vínculos presentes en la red Competición dicotomizada en distintos umbrales de corte. Para un umbral de $>5$ el valor es de $16,26 \%$, para un umbral de $>10$ es de $19,19 \%$ y para un umbral de $>15$ es de $23,62 \%$ (ver iError! No se encuentra el origen de la referencia.). Este resultado permite concluir que la probabilidad de que dos grupos de barras sean enemigos está vinculada a la cantidad de partidos disputados por sus instituciones deportivas, aunque no de una manera directa.

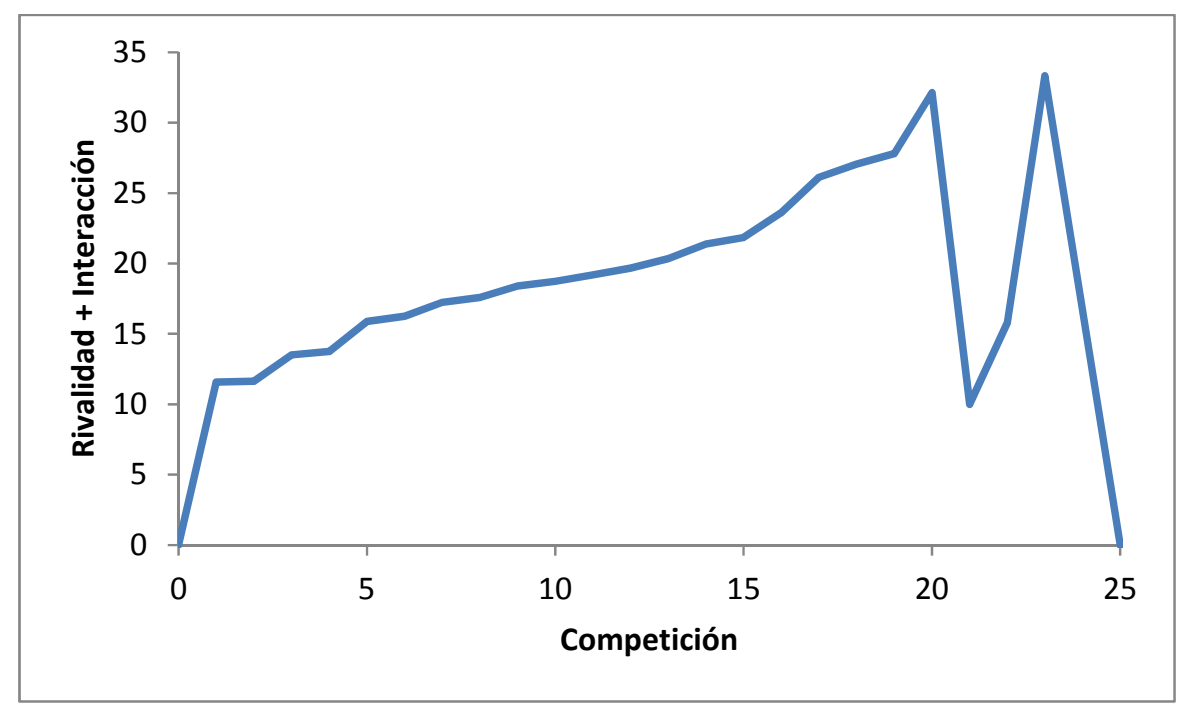

Gráfico 1. Rivalidades + Competición / Rivalidades. El gráfico muestra la cantidad de enemistades vinculadas con competencia deportiva (intersección de la red Rivalidad con la red Competición) en distintos

\footnotetext{
${ }^{13}$ Si bien se obtuvo casi la totalidad de los datos para los grupos de simpatizantes e instituciones de Capital Federal y Gran Buenos Aires, faltaron muchos datos de los grupos e instituciones del resto del país. Al realizar el análisis sobre una sub-red que contiene sólo los grupos e instituciones metropolitanos, los resultados avalan aún más la hipótesis propuesta. El 85,07\% de los vínculos en la sub-red Rivalidad están presentes entre mismos nodos en la sub-red Competición binarizada.
} 
umbrales de corte de la red Interacción. El descenso abrupto a partir del umbral de corte $>20$ se debe a que existen pocos equipos que hayan disputado más de 20 partidos en los últimos 10 años.

La distribución de los grados nodales no permite inscribir la red Rivalidad en el universo de las redes libre de escala. Sin embargo existe una tendencia a una distribución asimétrica que recuerda una ley de potencia, tanto en la distribución de grados $x$ ranking como en la de grados $x$ ocurrencias (ver iError! No se encuentra el origen de la referencia. 2 y Gráfico 3$)^{14}$. Existe una ligera tendencia a que las instituciones que más rivales enfrentaron en lo deportivo tengan más grupos de simpatizantes enemigos. Así lo indican casos como el de Almirante Brown de Isidro Casanova, Buenos Aires, grupo que tiene la mayor cantidad de enemigos (grado nodal de 21) y a su vez se identifica con el club que ocupa el quinto lugar en el ranking de equipos que más rivales enfrentaron en lo deportivo (en los últimos 10 años se enfrentó con otras 69 instituciones deportivas). Aunque no hay correlación entre el grado nodal en la red Rivalidad con el grado nodal en la red Competición (ver iError! No se encuentra el origen de la referencia.).

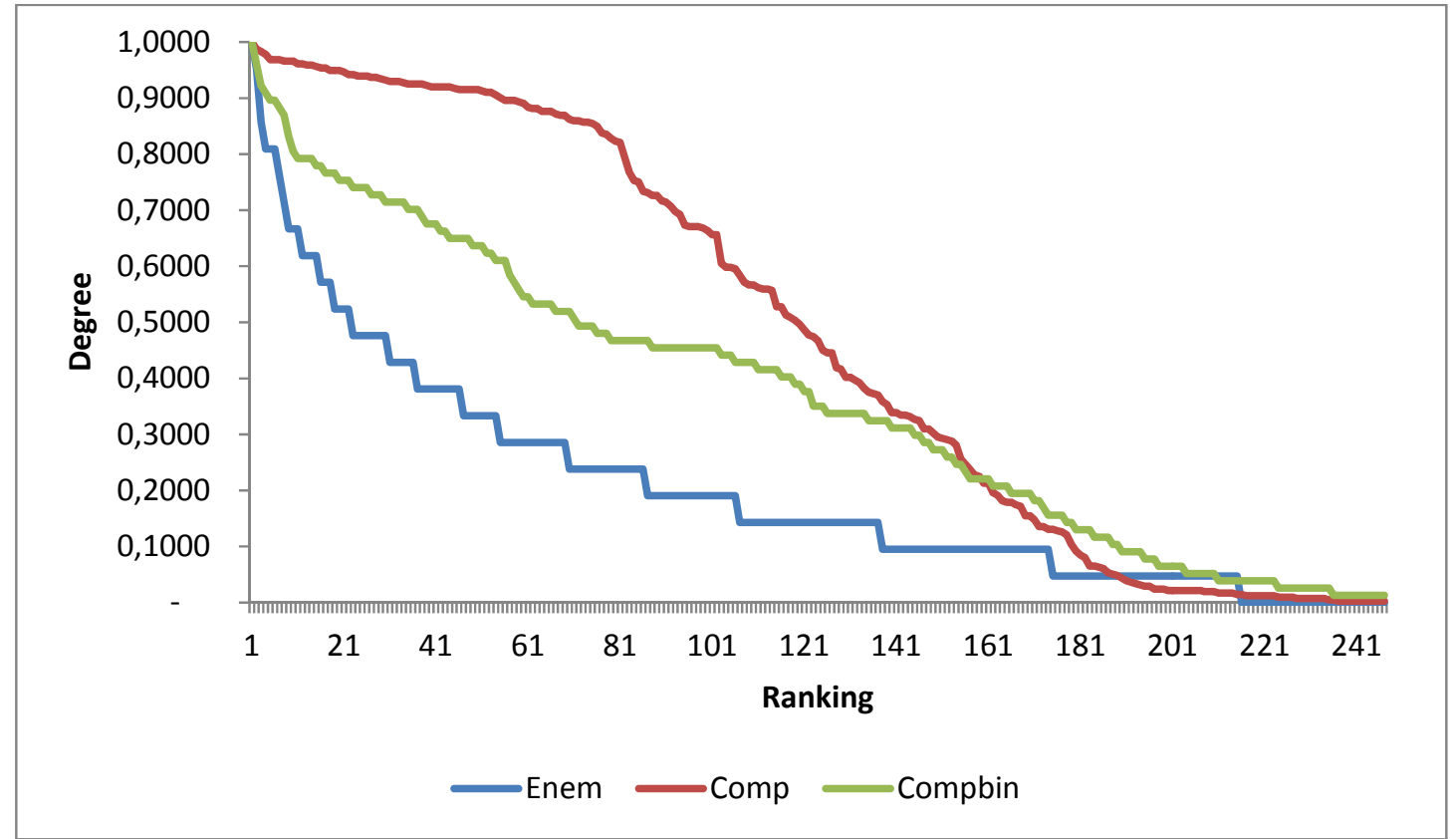

Gráfico 2. Degree normalizado por el ranking para las redes Rivalidad, Competición y Competición binarizada.

\footnotetext{
${ }^{14}$ La recolección de datos no abarcó la red total de manera que pueden existir sesgos muestrales en los datos. Esto se debió a que no estaban disponibles todos los datos en las webs revisadas. Es posible que la media del grado nodal en ambas redes sea mayor al indicado. Esto repercutiría en el análisis de las distribuciones nodales, el análisis de correlación y en el coeficiente de agrupamiento.
} 


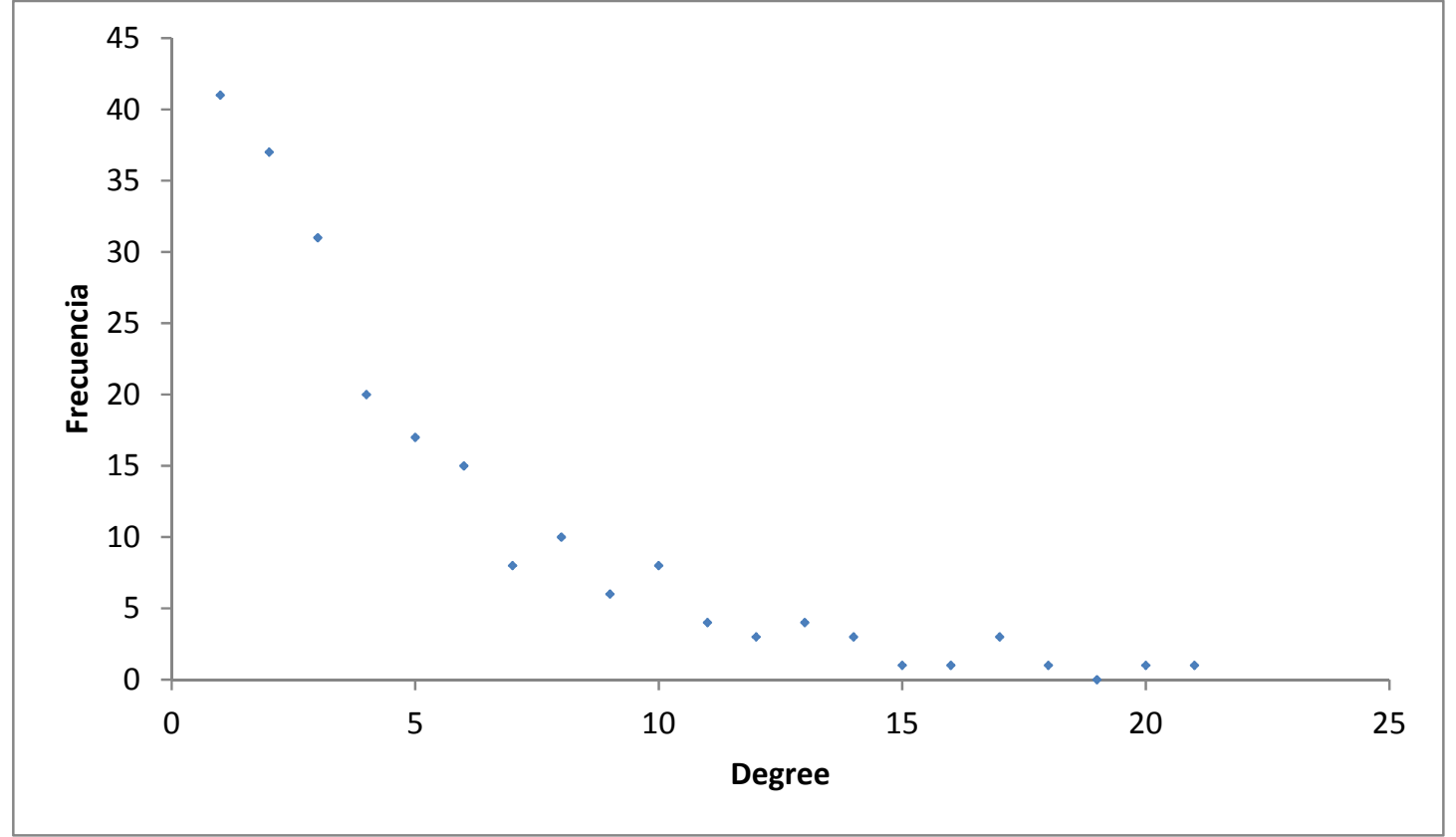

Gráfico 3. Distribución del degree de la red Rivalidad por la frecuencia. Se observa una ligera tendencia hacia una power law.

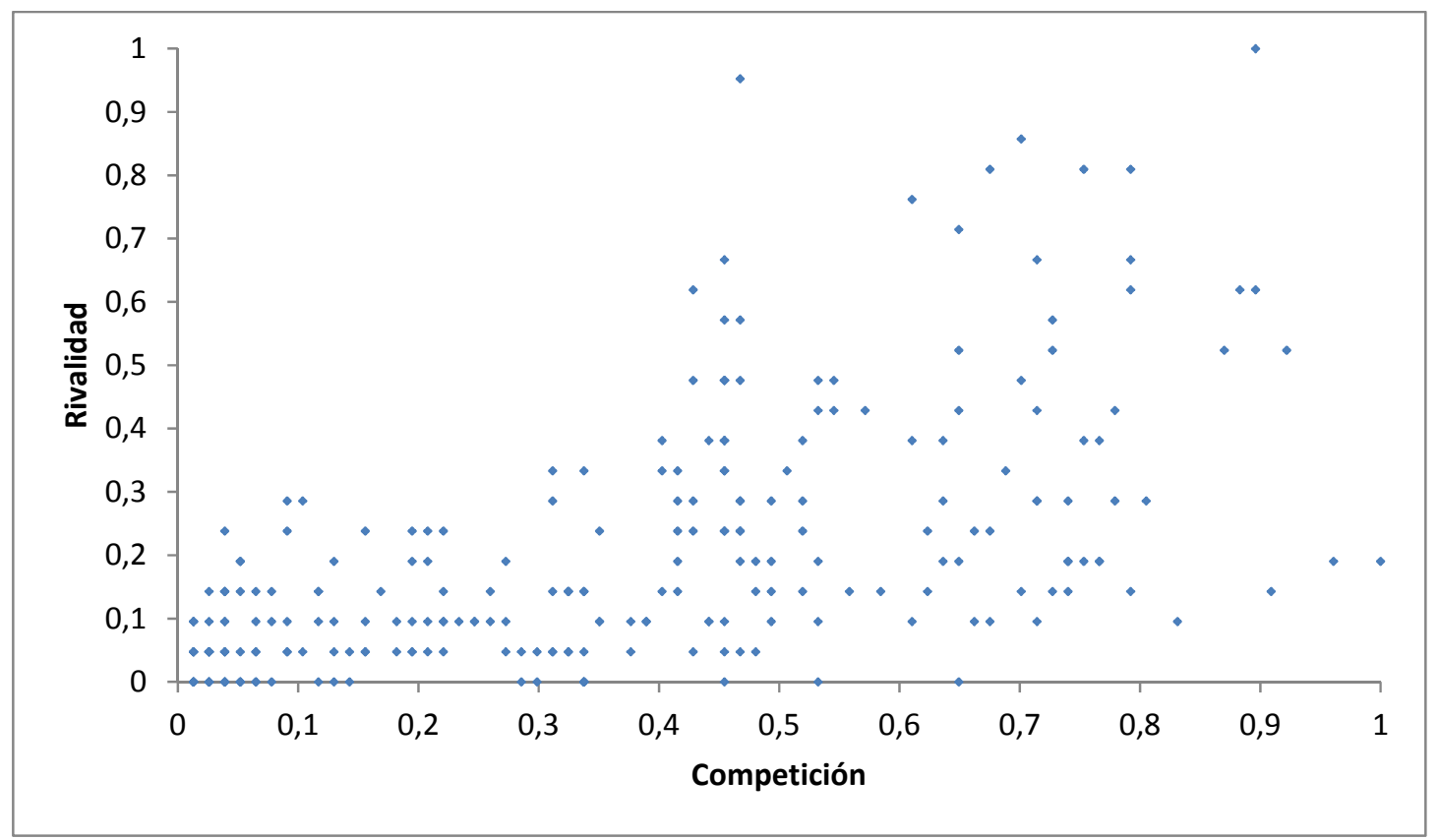

Gráfico 4. Rivalidad x Competición. Distribución de las correlaciones entre el degree normalizado de la red Rivalidad y la red Competición. No se observa correlación aunque una ligera tendencia a que las hinchadas que menos rivales enfrentaron en lo competitivo tengan menos enemigos. 
El análisis de homofilia ${ }^{15}$ permite clasificar a las barras en rivales cercanos (rivales que comparten el atributo territorial), rivales no cercanos (rivales que no comparten el atributo territorial), neutrales cercanos (no rivales que comparten el atributo territorial), y neutrales no cercanos (no rivales que no comparten el atributo territorial). Los cálculos de homofilia a partir de la pertenencia territorial provincial (atributo provincia) indican que el $60,69 \%$ del total de las enemistades se dan entre grupos que comparten la misma provincia (rivales cercanos). En cambio el procentaje de rivales cercanos sobre el total de barras cercanas sólo es del $6.03 \%$, siendo neutrales la amplia mayoría de las barras cercanas.

Los cálculos de homofilia a partir de la pertenencia territorial municipal (atributo ciudad) indican que el sólo el $10,69 \%$ de las enemistades se dan entre grupos que comparten la misma ciudad (rivales cercanos) y el resto son rivales inter-municipales. Sin embargo, el porcentaje de rivales cercanos sobre el total de barras cercanas arroja un resultado más elevado que en el nivel provincial, indicando que del total de barras que comparten una misma ciudad, el $19,08 \%$ son rivales. Esto indica que la tendencia a ser rivales es mayor en el nivel municipal que en el nivel provincial.

Comparando los resultados obtenidos en el análisis de la intersección de las redes Rivalidad y Competencia, y de los cálculos de homofilia entre la red Rivalidad y el atributo Provincia, se concluye que el $43,51 \%$ de las enemistades se presentan entre barras que comparten una misma provincia y cuyas instituciones deportivas han competido al menos una vez en los últimos 10 años. Este resultado indica que existe un solapamiento entre la rivalidad, la competencia y la pertenencia territorial provincial (ver Ilustración 3 e llustración 4).

\footnotetext{
15 Homofilia es un claro ejemplo de cómo conceptos desarrollados para el análisis de redes positivas deben reinterpretarse para tener algún sentido. Aquí homofilia se refiere a la tendencia a mantener un conflicto con actores que poseen los mismos atributos que ego.
} 


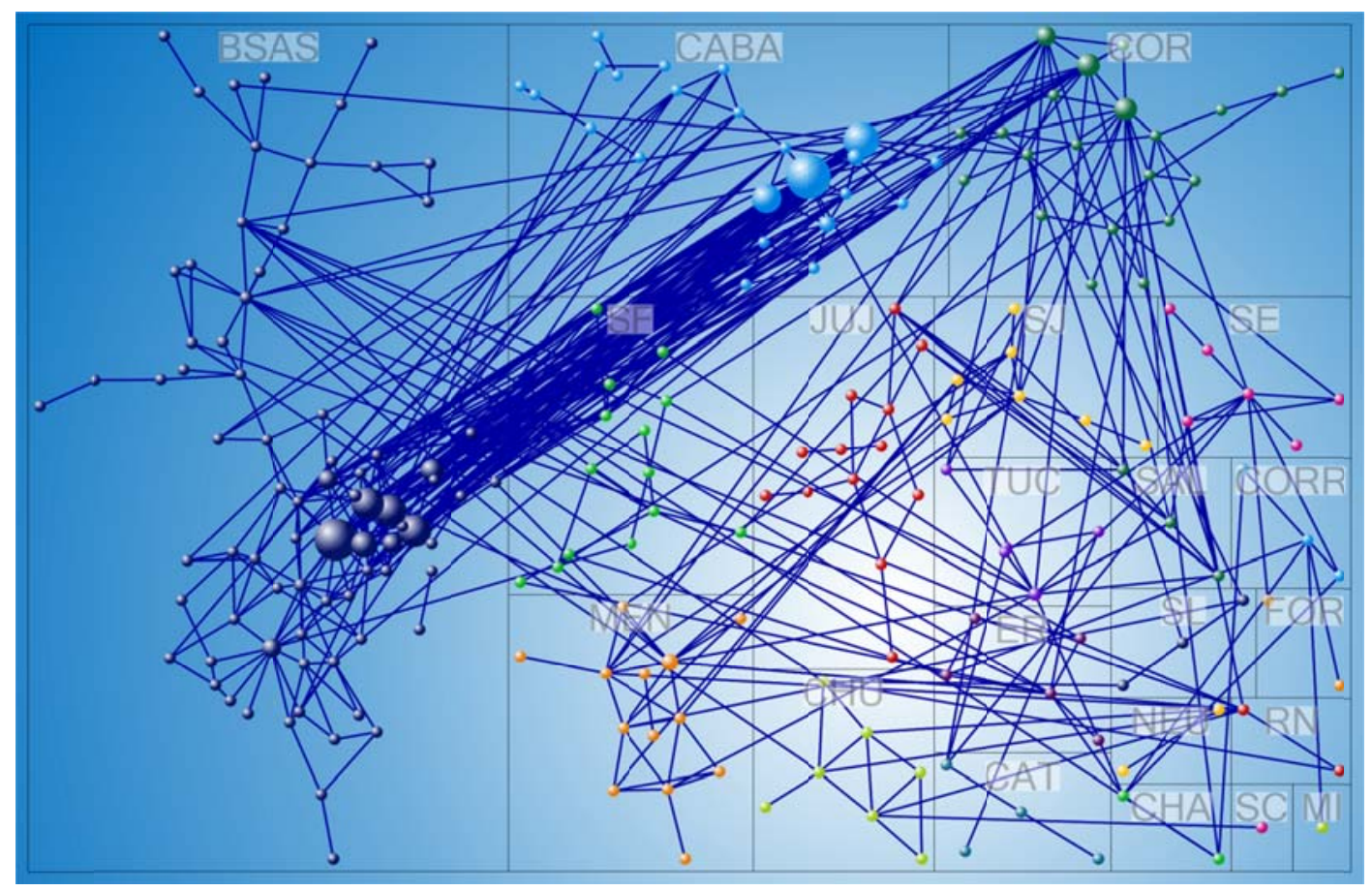

Ilustración 3. Red Rivalidad coloreada y agrupada por provincia de pertenencia, se muestran los vínculos interregionales.

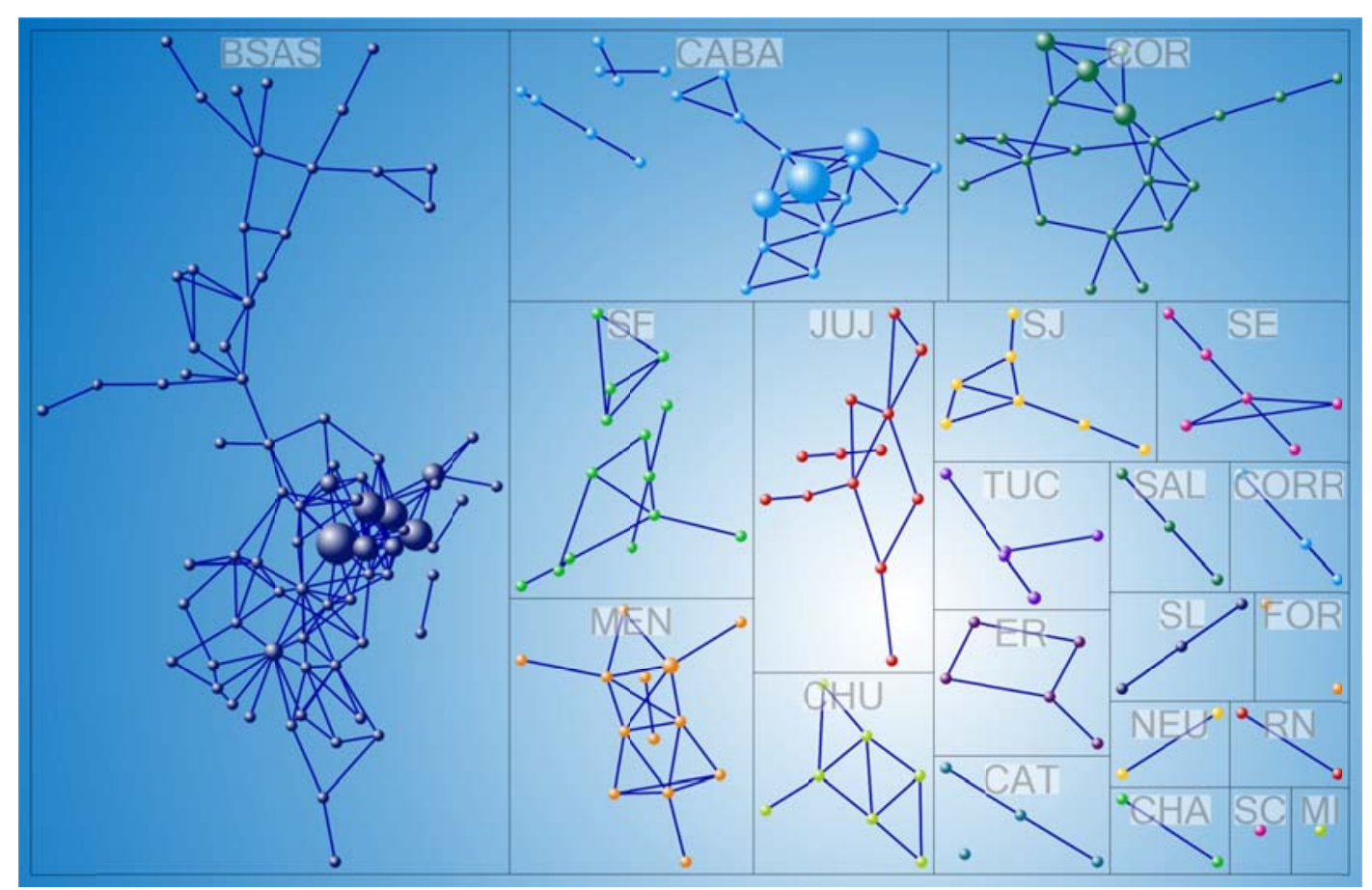

Ilustración 4. Red Rivalidad coloreada y agrupada por provincia de pertenencia, no se muestran los vínculos interregionales. 
Sin embargo, el mismo análisis antes expuesto realizado en base a la pertenencia municipal arroja resultados disímiles. En este caso sólo el 5,92\% de las enemistades se presentan entre barras que comparten la misma ciudad y cuyas instituciones deportivas han competido al menos una vez. La amplia mayoría de las enemistades se presentan entre rivales competidores no municipales $(71,18 \%)$. Esto puede deberse a la baja cantidad de rivales municipales en relación con el total. Para más detalles remitirse a la Tabla 2.

\section{Territorio}

\begin{tabular}{|c|c|c|c|c|c|c|}
\cline { 2 - 7 } & & Provincial & No provincial & Municipal & No Municipal & Total \\
\cline { 2 - 7 } & Competidores & 456 & 352 & 62 & 746 & 808 \\
& $\mathbf{4 3 , 5 1 \%}$ & $33,59 \%$ & $5,92 \%$ & $\mathbf{7 1 , 1 8 \%}$ & $\mathbf{7 7 , 1 0 \%}$ \\
\cline { 2 - 7 } Competencia & No & 180 & 60 & 50 & 190 & 240 \\
\cline { 2 - 7 } & competidores & $17,18 \%$ & $5,73 \%$ & $4,77 \%$ & $18,13 \%$ & $22,90 \%$ \\
\cline { 2 - 7 } & \multirow{2}{*}{ Total } & 636 & 412 & 112 & 936 & 1048 \\
& $\mathbf{6 0 , 6 9 \%}$ & $39,31 \%$ & $10,69 \%$ & $\mathbf{8 9 , 3 1 \%}$ & $100 \%$ \\
\hline
\end{tabular}

Tabla 2. Tipología de relaciones y valores absolutos y relativos a partir de los resultados del análisis de las redes Rivalidad y Competencia y los cálculos de homofilia. En la tabla sólo se representan los resultados del análisis de las 1048 relaciones de enemistad.

Por último es pertinente comparar los rivales competidores cercanos contra el total de competidores cercanos a nivel provincial y municipal. En relación al nivel provincial, el $16,06 \%$ de los competidores cercanos son rivales. En el nivel municipal este valor se eleva a 39,24\%. Estos resultados indican que a mayor proximidad geográfica y competencia deportiva la pertenencia territorial cobra importancia y aparece vinculada a complejos de actitudes hostiles frente a otros grupos de simpatizantes.

El sistema de categorías deportivas que impera en el fútbol argentino opera formando agrupamientos de instituciones en competición directa, que representan aproximadamente los límites divisionales y regionales de cada nivel competitivo. Los ascensos y descensos de categoría funcionan como "atajos" que conectan los agrupamientos. Este mecanismo genera un elevado coeficiente de agrupamiento y una baja media de la distancia en la red Competencia operando de manera similar al mecanismo propuesto por Watts y Strogatz (Watts \& Strogatz, 1998). Así mismo se genera un elevado solapamiento de la red Rivalidad sobre la red Competencia y una elevada homofilia entre barras enemigas que comparten el atributo Provincia. 


\section{Discusión}

La principal conclusión de este trabajo es que la competencia deportiva organizada regionalmente es el principal factor que condiciona la estructura de la red de rivalidades entre barras. Esta vinculación se manifiesta en distintas características de la red Rivalidad:

- El $77,10 \%$ de las rivalidades se dan entre grupos de barras que compitieron al menos una vez en los últimos 10 años.

- El incremento de la probabilidad de que dos grupos de barras sean enemigos ocurre en paralelo con el incremento de la competición $(23,62 \%$ de los grupos que compitieron en más de 15 ocasiones son rivales).

- El 60,69\% de las rivalidades se dan entre grupos de barras que comparten la misma provincia.

- El $19,08 \%$ de los grupos de barras que comparten una misma ciudad son rivales.

- El $43,51 \%$ de las rivalidades se dan entre grupos de barras que han competido y que comparten una misma provincia.

- El 39,24\% de las rivalidades se dan entre grupos de barras que han competido y que comparten una misma ciudad.

La competencia instrumental en lo deportivo es un factor indispensable para la emergencia de un conflicto social entre los grupos de simpatizantes. Es muy probable que dos instituciones vinculadas por una competencia deportiva tengan grupos de barras enemigos. Existe evidencia empírica que trágicamente apoya esta conclusión. La mayoría de los enfrentamientos que devienen en la muerte de un simpatizante ocurren en las inmediaciones del estadio durante o posteriormente al encuentro (26\%) o en los viajes hacia el estadio (21\%) (Murzi, Uliana, \& Sustas, 2011). Es decir que el $47 \%$ de las muertes en el fútbol argentino ocurren en el contexto de la competencia futbolística.

Sin embargo, buena parte de las rivalidades no se correlacionan con competencias deportivas en los últimos 10 años. Este dato admite al menos dos interpretaciones: la competencia deportiva condiciona limitadamente el establecimientos de rivalidades, o las rivalidades pueden haber surgido durante competencias deportivas hace más de 10 
años, y el sistema de descensos no ha reactualizado la competencia aunque la enemistad se mantiene ${ }^{16}$.

En el análisis presentado quedan fuera un conjunto de factores cuya influencia es importante determinar en el futuro. Uno de ellos es el papel de las alianzas preexistentes en la dinámica del conflicto entre barras. Otros factores no tenidos en cuenta se engloban en lo que Giulianotti llamó las líneas de fractura históricas (1999): las adscripciones político-sindicales, las oposiciones socio-económicas y las orientaciones ideológicas. Por último quedan pendientes la capacidad de convocatoria, la visibilidad mediática y el éxito deportivo-económico. Estos últimos factores afectan el desempeño deportivo $y$, por lo tanto, afectan de manera indirecta la permanencia de las instituciones en las categorías deportivas.

Ya que las rivalidades están estrechamente vinculadas a la competencia deportiva es necesario profundizar en el análisis de la dinámica de la red Competencia. Gil ha mostrado que la estructura de los campeonatos en Argentina reproduce modelos de centro-periferia que benefician a las instituciones de Capital Federal y Gran Buenos Aires. Además el sistema de descensos por promedios trianuales beneficia a las instituciones económicamente poderosas incrementando la brecha entre los equipos de Primera A y el resto (Gil, 2008b). Como consecuencia, las instituciones económicamente poderosas se desempeñan en instancias competitivas nacionales, mientras que el resto lo hacen en instancias regionales. Esto repercute en el tipo de rivalidades que establecen los grupos de simpatizantes: rivalidades inter-regionales entre grupos identificados con instituciones adscriptas a las primeras divisiones, y rivalidades intra-regionales para grupos identificados con instituciones en las divisiones inferiores (Bundio, 2011). El elevado nivel de conflicto regional identificado etnográficamente por Garriga puede deberse a este hecho (2002). Asimismo resta indagar la manera en que los cambios en los sistemas de descensos influyen en la evolución del conflicto entre grupos de simpatizantes.

Investigadores como Stuinverberg han afirmado que los grupos de simpatizantes establecen enemistades a partir de la proximidad geográfica, siendo las rivalidades más fuertes las que se dan entre grupos que son del mismo barrio o ciudad (2008). Sin embargo, la organización regional de los torneos argentinos, sumada al hecho de que el $46,56 \%$ de los grupos se ubican en Capital Federal y la provincia de Buenos

\footnotetext{
${ }^{16}$ Un ejemplo de esto es el caso de la enemistad entre los barras de Ferro Carril Oeste y Velez Sarfield, clubes que no compiten desde el año 200 y que sin embargo mantienen una hostilidad recíproca.
} 
Aires, puede explicar el elevado grado de homofilia de la red Rivalidad con respecto a la pertenencia territorial. Después de todo el $43,51 \%$ de las rivalidades se dan entre grupos que comparten una provincia y que además compiten entre sí.

Además es corriente que los conflictos suscitados en el evento deportivo se trasladen al vecindario durante la semana posterior al evento, de manera que dos grupos de simpatizantes vecinos tienen más probabilidades de establecer una enemistad. En este aspecto los grupos de simpatizantes argentinos difieren de sus pares españoles, que muestran un patrón territorial definido de afinidades donde el Real Madrid es más afín a simpatizantes de otros clubes de Madrid y Andalucía, mientras que el Barcelona es más afín a simpatizantes Cataluña, Navarra y el País Vasco (Maya \& Bohórquez, 2011). ${ }^{17}$

Esta elevada concentración regional podría ser el factor que impide que se generalice la lógica del enemigo común, tal como señaló Garriga (2002). Esta lógica señala que debería encontrarse una frecuencia significativa de estructuras balanceadas como tríadas con dos enemistades y una amistad, de acuerdo a los desarrollos de la teoría de Heider (Cartwright \& Harary, 1956). Si bien la presencia de estas tríadas balanceadas es significativa, su alcance el muy limitado y no llega a ser un factor de peso que explique la estructura de la red de rivalidades (Bundio, 2012a). De hecho las tríadas más comunes son aquellas de vinculan a tres grupos por lazos de rivalidad, mostrando que en el campo de las hinchadas el conflicto es la norma.

Es necesario reflexionar sobre el uso de conceptos y métricas de ARS ideadas para analizar redes positivas. En efecto, las métricas de ARS son independientes del contexto. Ello vuelve absolutamente necesario la contextualización de los datos y de los resultados del análisis. Por ejemplo, el sentido de métricas como la homofilia es completamente diferente en el caso de las redes negativas. Otro tanto ocurre con el grado nodal, que lejos de representar la influencia social en la red, está indicando la elevada conflictividad de ese nodo.

Además similares características topológicas complejas (como la pequeña media de las distancias geodésicas, el elevado coeficiente de agrupamiento, y la distribución potencial de los grados nodales), pueden esconder una variedad de mecanismos constitutivos y procesuales que le dan forma a las estructuras reticulares encontradas.

17 Se debe tener en cuenta que en el caso del estudio español se están midiendo simpatías entre simpatizantes mientras que en el presente estudio se conciben a las afinidades como alianzas y a las hostilidades como rivalidades entre grupos sociales específicos: barras bravas. 
Tal como advierte Watts, es necesario reconstruir los mecanismos constitutivos que llevaron a la red a tener la forma que tiene, y no inferir la actuación de mecanismos similares en redes que exhiben propiedades similares (2006). Esto es más cierto aún en el caso de las redes negativas que requieren nuevos marcos interpretativos que le den un sentido a los resultados obtenidos en el análisis.

Los resultados de este trabajo permiten avanzar con la modelización de redes negativas como redes complejas. Aunque la adecuación del modelo de Watts y Strogatz al caso de las redes de barras bravas depende de los factores exógenos que condicionan la estructura de la red negativa (competencia deportiva y cercanía greográfica). En efecto, la conclusión principal de este trabajo es que la organización de la competencia condiciona la estructura de la red Rivalidad, no es la dinámica propia de esta red el principal factor estructurante. A pesar de que el mecanismo no es similar al propuesto por Watts y Strogatz para el estudio de redes positivas, es suficiente para generar un efecto de mundo pequeño en la red negativa.

En el fenómeno de las rivalidades entre barras bravas existe un mecanismo generador de agrupamiento (la organización de la competencia deportiva a nivel de las instituciones deportivas) y un mecanismo que genera una pequeña media de la distancia (los ascensos y descensos de categoría deportiva). Estos dos factores constituyen los dos mecanismos gracias a los cuales la red Rivalidad adquiere características de mundo pequeño. El desarrollo de la red Rivalidad es un desarrollo condicionado por la organización específica del sistema de competencia deportiva.

Se puede afirmar que si la competencia deportiva se organizara de manera aleatoria, las rivalidades entre grupos de simpatizantes adquirirían la forma de una red aleatoria, tal como se concluía previamente a partir de los datos etnográficos. Esta conclusión abre la puerta a la construcción de modelos predictivos que indaguen de forma aproximada el desarrollo futuro del conflicto entre grupos de simpatizantes. De esta manera el análisis de redes negativas podría contribuir a disminuir el elevado nivel de violencia del fútbol argentino.

\section{Referencias bibliográficas}

Alabarces, P. (2004). Crónicas del aguante: fútbol, violencia y política (1a ed.). Buenos Aires: Capital Intelectual. 
Alabarces, P.; Garriga, J. \& Moreira, M. V. (2008). "El "aguante" y las hinchadas argentinas: una relación violenta". Horizontes Antropológicos. Antropología e Esporte, 14(30), 113-136.

Albert, R. \& Barabási, A.-L. (2002). "Statistical mechanics of complex networks". Reviews of Modern Physics, 74(1), 47-97.

Barabási, A.-L. \& Albert, R. (1999). "Emergence of Scaling in Random Networks". Science, 286(5439), 509-512.

Bergemann, P. (2012, Abril 2012). Networks of Accusations during the Spanish Inquisition. Ponencia presentada en Negative Ties and Social Networks Workshop, Corvinus University of Budapest.

Bundio, J. S. (2011). "Conflictos y alianzas entre hinchadas argentinas: apuntes metodológicos para el testeo de hipótesis mediante Análisis de Redes Sociales". Lecturas Educación Física y Deportes, 16(155). Disponible en: http://www. efdeportes.com/efd155/conflictos-y-alianzas-entre-hinchadasargentinas.htm

Bundio, J. S. (2012a). "El enemigo de mi enemigo es mi amigo. Explorando los conflictos y las alianzas entre hinchadas de fútbol". Lecturas Educación Física y Deportes, 15(167). Disponible en http://www.efdeportes.com/efd167/alianzasentre-hinchadas-de-futbol.htm

Bundio, J. S. (2012b). "El Pequeño Mundo de las hinchadas de fútbol". En N. Kuperszmit; T. L. Mármol, L. Mucciolo \& M. Sacchi (Eds.), Entre Pasados y Presentes III. Estudios Contemporáneos en Ciencias Antropológicas. Buenos Aires: Instituto Nacional de Antropología y Pensamiento Latinoamericano.

Cartwright, D. \& Harary, F. (1956). "Structural balance: a generalization of Heider's theory". Psychological Reviews, 63(5), 277-293.

Clauset, A.; Rohilla, C. \& Newman, M. E. J. (2009). “Power-law distributions in empirical data". SIAM Rev., 51(4), 661-703.

Erdös, P. \& Rényi, A. (1959). “On Random Graphs". Publicationes Mathematicae, 6(Diciembre 2009), 290-297.

Ferrer i Cancho, R. \& Solé, R. V. (2001). "The small world of human language". Proceedings of the Royal Society of London B, 268(1485), 2261-2265. 
Garriga, J. (2002). "Amistades entre hinchadas. Violencia, masculinidad y vínculos de amistad de un grupo de simpatizantes del fútbol argentino". Lecturas Educación Física y Deportes, 8(55). Disponible en http://www. efdeportes.com/efd55/hinchada.htm

Garriga, J. (2007). Haciendo amigos a las piñas: violencia y redes sociales de una hinchada de fútbol. Buenos Aires: Prometeo Libros.

Gil, G. J. (2008a). "La pasión según Aldosivi. El "otro" y los combates por la identidad". Horizontes Antropológicos. Antropología e Esporte, 14(30), 137-164.

Gil, G. J. (2008b). "Sobre la estructura organizativa de los campeonatos oficiales de fútbol en Argentina: del estado de injusticia actual a una propuesta alternativa". Revista Internacional de Ciencias del Deporte, 4(11), 17.

Giulianotti, R. (1999). Football. A Sociology of the Global Game. Cambridge: Polity Press.

Heider, F. (1946). "Attitudes and Cognitive Organization". The Journal of Psychology, 21, 107-112.

Joshi, A.; Labianca, G. \& Caligiuri, P. M. (2002). "Getting along long distance: understanding conflict in a multinational team through network analysis". Journal of World Business, 37(4), 277-284.

Kaiser, M. (2008). "Mean clustering coefficients: the role of isolated nodes and leafs on clustering measures for small-world networks". New Journal of Physics, 10(2008), 1-11.

Labianca, G. \& Brass, D. J. (2006). "Exploring the social ledger: negative relationship and negative asymmetry in social networks in organizations". Academy of Management Review, 31(3), 596-614.

Lusseau, D. (2003). "The emergent properties of a dolphin social network". Proceedings of the Royal Society of London B (Suppl.), 270(Suppl. 2), S186S188.

Maya, I. \& Bohórquez, R. (2011). Alternativas a la estadística tradicional en deportes de equipo. Indicadores de trabajo colectivo. Ponencia presentada en XIII Congreso Andaluz de Psicología de la Actividad Física y el Deporte.

Moreira, M. V. (2001). “Aguante y Honor: la visión nativa”. Lecturas Educación Física y Deportes, 7(36). Disponible en http://www. efdeportes.com/efd36/aguante.htm 
Moreira, M. V. (2005). "Trofeos de guerra y hombres de honor". En P. Alabarces (Ed.), Hinchadas (pp. 91-104). Buenos Aires: Prometeo Libros.

Murzi, D.; Uliana, S. \& Sustas, S. (2011). “El fútbol de luto. Análisis de los factores de muerte y violencia en el fútbol argentino". En M. Godio \& S. Uliana (Eds.), Fútbol y sociedad: prácticas locales e imaginarios globales (1a ed. ed., pp. 175-196). Sáenz Peña: EDUNTREF.

Nakamura, K.; Tita, G. \& Krackhardt, D. (2011). "Violence in the "Balance": A Structural Analysis of How Rivals, Allies, and Third-Parties Shape Inter-Gang Violence". Heinz College Working Paper Series, 1-41.

Newman, M. E. J. (2001). "The structure of scientific collaboration networks". Proceedings of the National Academy of Sciences, USA 98(2), 404-409.

Papachristos, A. V. (2009). "Murder by Structure: Dominance Relations and the Social Structure og Gang Homicide". American J ournal of Sociology, 115(1), 74-128.

Robins, G. \& Pattison, P. (2006). Multiple networks in organizations. Melborune: University of Melbourne.

Stuivenberg, J. (2008). Fútbol; Rivalry and Fan Identification in Rosario, Argentina. Utrecht University, Utrecht.

Sustas, S. (2011). "Planos y lógicas de la violencia en el fútbol. Análisis y descripción de los enfrentamientos en que suceden las muertes en la Argentina". En M. Godio \& S. Uliana (Eds.), Fútbol y sociedad: prácticas locales e imaginarios globales (1a ed. ed., pp. 197-216). Sáenz Peña: EDUNTREF.

Watts, D. (2006). Seis Grados de Separación. La Ciencia de las Redes en la Era del Acceso. Barcelona: Paidós Ibérica.

Watts, D. \& Strogatz, S. H. (1998). "Collective dynamics of "small-world" networks". Nature, 393(4), 440-442. 